\title{
Indigenous Phosphate Solubilizing Bacteria from Peat Soil for an Eco-friendly Biofertilizer in Oil Palm Plantation
}

\author{
Elizabeth Caroline Situmorang ${ }^{\mathrm{a}^{*}}$, Andriessa Prameswara $^{\mathrm{a}}$, Hana Christine Sinthya ${ }^{\mathrm{a}}$, \\ Nurita Toruan-Mathius ${ }^{\mathrm{a}}$ and Tony Liwang ${ }^{\mathrm{a}}$
}

Plant Production and Biotechnology ,PT. SMART Tbk., Sinar Mas Land Plaza, $2^{\text {nd }}$ Tower, $10^{\text {th }}$ floor, JL MH. Thamrin No. 51, Kav. 22, Jakarta 10350, Indonesia

\begin{abstract}
Degradation in soil fertility is an enormous problem in agricultural intensification system. Availability in phosphate is one of among encountered problems. Peat soils have large areas and great potential for agriculture and plantations, but have many obstacles in their management. One of the issues is the low soil fertility and low availability of nutrients, especially phosphate which exists in many organic forms that are not available to plants. Phosphorous is an essential element after nitrogen, which plays an important role in plant growth and metabolism and the process of soil microbiology. Introduction of phosphate- solubilizing bacteria (PSB) as biofertilizer, is a renewable energy based which can increase the availability of phosphate to plants can overcome this problem and at the same time reducing the use of inorganic P fertilizer. Indigenous PSB, isolated from palm oil plantation could be used as a better and friendly bio-agent to improve soil fertility, specifically for phosphate availability. Eight PSB have been isolated from peat soil in oil palm platation. Morphological, biochemical characterization and molecular identifications showed that the 8 isolates belonged to Flavobacterium and Enterobacter genera, more precisely the species of Burkholderia sp and Novosphingobium nitrogenifigens. Characterization of isolates of the highest PSB activity consisted of the ability to dissolve phosphate in Pikovskaya solid medium, temperature resistance optimization and the ability to produce phosphatase enzyme. Results showed that isolate with the highest potentiality of dissolving phosphate formed $3.5 \mathrm{~cm}$ of clear zone diameter and the phosphatase activity at 9 days of incubation $5.992 \mathrm{units}(\mu \mathrm{mol} / \mathrm{ml} / \mathrm{min})$. The peak of enzyme's activity was reached at 6 days, which corresponded to $54.782 \mathrm{ppm}$ of phosphorus solubilised. The lowest $\mathrm{pH}$ (3.2) was reached at $1^{\text {st }}$ day of incubation. These isolates showed the ability to grow optimally at temperature range of 25 to $30^{\circ} \mathrm{C}$. Indigenous PSB could be used as biofertilizer agents which are eco friendly.
\end{abstract}

\footnotetext{
* Corresponding Author: Tel: +62-813-820-20600

Email: situmorang_elizabeth@yahoo.com
}

ISSN 2413-5453 (c) 2015 The Authors. 


\section{Introduction}

Energy crises and high price of fertilizers and more dramatically with low purchasing power of farmers tends to look for other more economically nutrient source. Bio fertilizer based on renewable energy sources is an alternative with low cost to the use of inorganic fertilizer [1]. This can help to economise the high cost needed for fertilizers use including phosphorus nutrients.

One of the major macronutrients used by plants is phosphorus $(\mathrm{P})$. Intensive agriculture system tends to use massive nutrients in soil and limite the availability of nutrients. $P$ is reported play an important role in nitrogen fixation process from atmosphere which needs large amount of energy [2]. $\mathrm{P}$ is essential to harness the yield potential. Lack of $\mathrm{P}$ will inhibit plant growth.

In agricultural practices, phosphate fertilizers are used to add P into the soil. High P content in soil given by fertilizer cannot be totally available for plant roots due to fixed and precipitated $\mathrm{P}$ [3] , Around 75-90 percent of $\mathrm{P}$ fertilizer turns to precipitation caused by $\mathrm{Fe}, \mathrm{Al}$ and $\mathrm{Ca}$ complexes presence in soil [4]. The precipitation which converts rapidly $\mathrm{P}$ into soluble complexes in the soil such as iron phosphate, aluminium phosphate and calcium phosphate makes them unusable for plant. High rate of unavailable $\mathrm{P}$ leads to apply phosphate fertilizer more frequently.

Energy required to for production of chemical phosphate fertilizers amounted to 4 million dollars per annum [5]. Introduction of biofertilizer into soil is an alternative [6]. Because not only the positive effects of biofertilizers on the physical, chemical and biological properties of soil, biofertilizers also save on expensive inputs which are currently consumed from non-renewable energy sources [5]. For this consideration, it is necessary to develop an economical and also eco-friendly fertilizer product [7].

Some microorganisms have capability to liberate inorganic phosphate from soil mineral matrix and render those $\mathrm{P}$ more available to plant [8], and also act as plant growth promoting rhizobacteria which can improve plant growth [4]. At the same time they could reduce the use of chemical fertilizer and keep environment.

Some phosphate solubilizing bacteria (PSB) which have been isolated from soil were from genera Flavobacterium, Pseudomonas, Aerobacter, Bacillus, Enterobacter, Agrobacterium, Rhizobium, Erwinia, Achromonas, and Micrococcus [9]. The mechanism of phosphate solubilization is still unclear, but nevertheless production of organic acids seems to be responsible for solubilizing phosphate in soil. Burkholderia sp. was reported as the most efficient isolate of PSB, based on biochemical characteristics, FAME analysis and 16S rDNA typing, which produced gluconic acid to release phosphate complexes [10].

Using indigenous microorganisms as biofertilizer in oil palm plantation is the best way, as microbes are specific and highly dependant of their environment. The isolation of indigenous phosphate solubilizing bacteria is then significant and necessary to develop biofertilizer formula [11]. This study consisted of isolation and characterization of indigenous phosphate solubilizing bacteria from peat soil in an oil palm plantation.

\section{Materials and methods}

\subsection{Soil sample and bacteria isolation}

Peat soil was sampled from an oil palm plantation located in Riau, Indonesia. Geographical 
coordinates were $101^{\circ} 6^{\prime} 0$ " E / $0^{0} 46^{\circ} 0$ " N. Samples were taken from 10 locations of saprist peat soil with $10,000 \mathrm{~m}^{2}$ sampling area. Sampling procedure followed zig zag method. Samples were taken from $20 \mathrm{~cm}$ of depth, 1 meter away from oil palm by dissecting oil palm fresh roots. Adhering soil on roots was used as sample to isolate phosphate solubilizing bacteria following Rao and Sinha method [12] using Pikovskaya as selection media and $\mathrm{CaHPO}_{4}$ as $\mathrm{P}$ source.

\subsection{Isolates identification}

Identification of phosphate solubilizing bacteria was conducted first using morphological observation, consisted of colour, colony form, elevation, edge, surface and optical and microscopic characteristic to characterize Gram type and bacterial cell form. Colony was enumerated following Standard Plant Count method. Physiological characterisation was then done following Oxoid guidance consisted of Indole, MR-VP, catalase, and Phenilalanine desaminase activity, motility and use of $\mathrm{O}_{2}$. The identification was done using Bergey's Manual of Determinative Bacteriology $9^{\text {th }}$ Edition [13]. Molecular identification was carried out by amplification of $16 \mathrm{~S}$ rRNA and using $9 \mathrm{~F}$ and $1510 \mathrm{R}$ as primers.

\subsection{Characterization of $P S B$}

Capacity of PSB in solubilising P on Pikovskaya solid medium was carried out by measuring clear zone diameter and phosphate solubilising index (PSI). One loop of PSB culture was incubated in 1 $\mathrm{ml}$ Nutrient Broth medium, shaked for 15 minutes at $150 \mathrm{rpm}$ and incubated at $30^{\circ} \mathrm{C}$ for 24 hours. $1 \mu \mathrm{l}$ of suspension was dropped on solid Pikovskaya medium and incubated for 7 days at room temperature. Visual observation was done during 7 days consisted of colony's form, edge, elevation, and colour. Diameter of clear zone surrounding colonies was also noted.

\subsection{Measurement of phosphate solubilising capacity}

Isolate with the highest phosphate solubilising index was selected for further observation and optimization. Best growth temperature was obtained by inoculating isolate on Nutrient Broth media and incubated at $4^{\circ} \mathrm{C}, 25^{\circ} \mathrm{C}, 30^{\circ} \mathrm{C}, 37^{\circ} \mathrm{C}$ and $50^{\circ} \mathrm{C}$. Optical density representing isolate's growth was measured at wave length $600 \mathrm{~nm}$ every 24 hours during 9 days. Bacterial culture was then pour-plated on Pikovskaya solid medium in several dilutions to confirm isolates' viability by enumerating colonies.

Quantification of phosphate solubilising capacity was done by two methods, first measuring solubilised phosphate using ICP-OES instrument and observing $\mathrm{pH}$ evolution during 9 days of incubation at the best temperature growth obtained previously. The second method consisted of measuring production of phosphatase enzyme, according to Tabatai and Bremner [14]. A standard curve using p-nitrophenol (p-NP) measured at $\lambda 410 \mathrm{~nm}$ was dressed for measuring enzyme activity.

\section{Results and discussion}

Screening of PSB on Pikovskaya solid medium after 48 hours incubation was based on clear zone formation surrounding isolates (Fig. 1) which represented phosphate solubilisation containing $\mathrm{CaHPO}_{4}$ in medium. Colonies were selected and counted following standard plate count method. 
PSB enumeration was $3.38 \times 10^{7} \mathrm{CFU} / \mathrm{g}$ of soil. Fifteen PSB isolates forming clear zone were then purified on Pikovskaya solid medium.

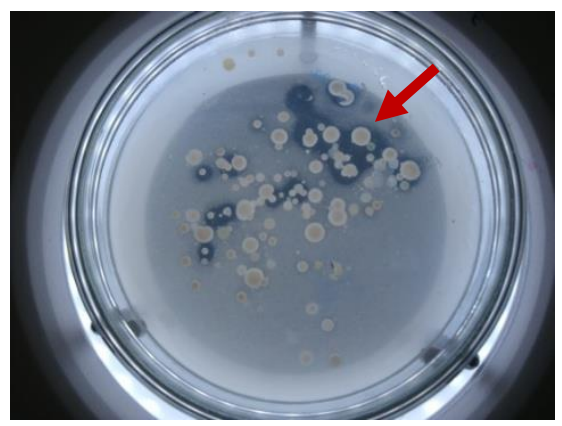

Fig. 1. Selection of phosphate solubilising bacteria on Pikovskaya medium

Qualitative analysis consisted of measuring phosphate solubilising index (PSI) which represented diameter of clear zone formed by each isolate (Fig. 2). Morphological characterization was observed according to Bergey's Manual of Systematic Bacteriology consisted of form, edge, elevation, which was shown in Table 2 . Those 15 isolates represented different morphological characters. The best phosphate soulubilizing index was TG2 PSB isolate representing $3.5 \mathrm{~cm}$ of clear zone diameter. Eight isolates have been selected according to different visual morphological characters, TG2, TG7, TG9, TG3, TG5, TG8, TG11 and TG12. All of them were Gram negative bacteria, having form bacilli, facultative anaerob and motile. They were from two genera, Flavobacterium and Enterobacter. The difference among them consisted of biochemical characterization in Methyl Red and Voges Proskauer tests in TG11 and TG12. These reactions were designated to differentiate between members of the coli-aerogens group. Both test are based on the detection of specific breakdown products of carbohydrate metabolism. All members of Enterobacteriaceae are by definition, glucose fermenters, and in MRVP broth after 18-24 hours incubation, fermentation produces acidic metabolic by products. Therefore, initially, all enteric bacteria will give positive MR reaction if tested. However, after further incubation, required by the test procedure (2-5 days), these bacteria will be divided into two categories, MR positive and MR negative. TG11 was MR negative enteric bacteria.

Table 1. Morphological characteristics of selected isolates

Flavobacterium and Enterobacterium genera were reported as phosphate solubilizing bacteria [7]. Eight isolates have been characterized and identified according to biochemical properties. Genera

Tabel 2. Note: $M R V P=$ Methyl Red and Voges Proskauer tests, Phe $=$ Phenylalanine test 


\begin{tabular}{|c|c|c|c|c|c|c|c|c|c|}
\hline Isolates & Gram & Form & $\mathrm{O}_{2}$ use & Motility & Indol & MRVP & Catalase & Phe & Genera \\
\hline TG2 & negative & bacilli & Facultative anaerob & motile & - & + & + & - & Flavobacterium \\
\hline TG7 & negative & bacilli & Facultative anaerob & motile & - & + & + & - & Flavobacterium \\
\hline TG9 & negative & bacilli & Facultative anaerob & motile & - & + & + & - & Flavobacterium \\
\hline TG3 & negative & bacilli & Facultative anaerob & motile & - & + & + & - & Flavobacterium \\
\hline TG5 & negative & bacilli & Facultative anaerob & motile & - & + & + & - & Flavobacterium \\
\hline TG8 & negative & bacilli & Facultative anaerob & motile & - & + & + & - & Flavobacterium \\
\hline TG11 & negative & bacilli & Facultative anaerob & motile & - & - & + & - & Enterobacter \\
\hline TG12 & negative & bacilli & Facultative anaerob & motile & - & + & + & - & Flavobacterium \\
\hline
\end{tabular}

identification has been done following Bergey's Manual Of Determinative Bacteriology $9^{\text {th }}$ Edition [1] and showed that Flavobacterium and Enterobacterium were in the samples. Gram staining showed all isolates were Gram negative bacteria (Fig. $3)$.

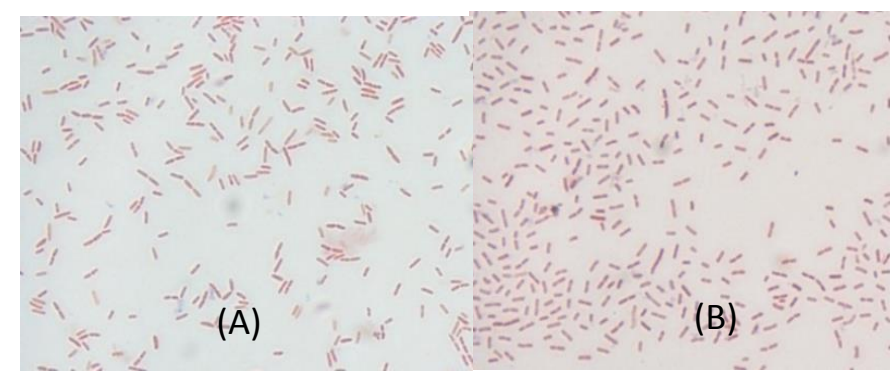

Figure 3. Gram staining of Flavobacterium (A) and Enterobacter (B)

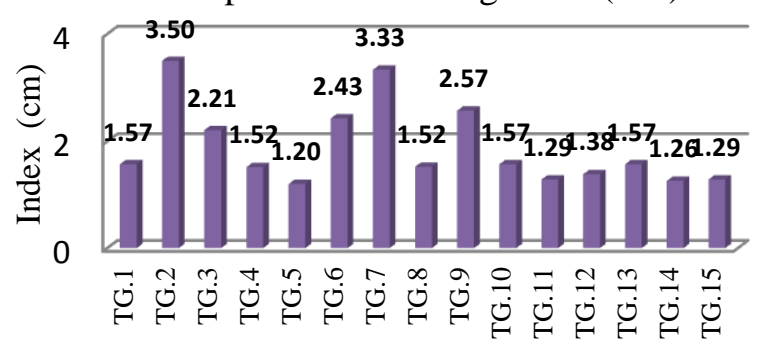

PSB isolates

Figure 2. Phosphaste solubilizing index of fifteen PSB isolates 
Table 3. Molecular identification of phosphate solubilizing bacteria

\begin{tabular}{cccc} 
& \multicolumn{3}{c}{ Maximum } \\
Isolates & Query cover & $\begin{array}{c}\text { Maxification } \\
\text { Identificity }\end{array}$ & Identity \\
\cline { 2 - 4 } TG7 & 100 & 99 & Burkholderia $\mathrm{sp}$ \\
TG9 & 98 & 99 & Burkholderia $\mathrm{sp}$ \\
TG3 & 97 & 99 & Burkholderia $\mathrm{sp}$ \\
TG5 & 98 & 99 & Burkholderia $\mathrm{sp}$ \\
TG8 & 98 & 99 & Burkholderia $\mathrm{sp}$ \\
TG11 & 98 & 99 & Burkholderia $\mathrm{sp}$ \\
TG12 & 100 & 97 & Novosphingobium \\
nitrogenifigens
\end{tabular}

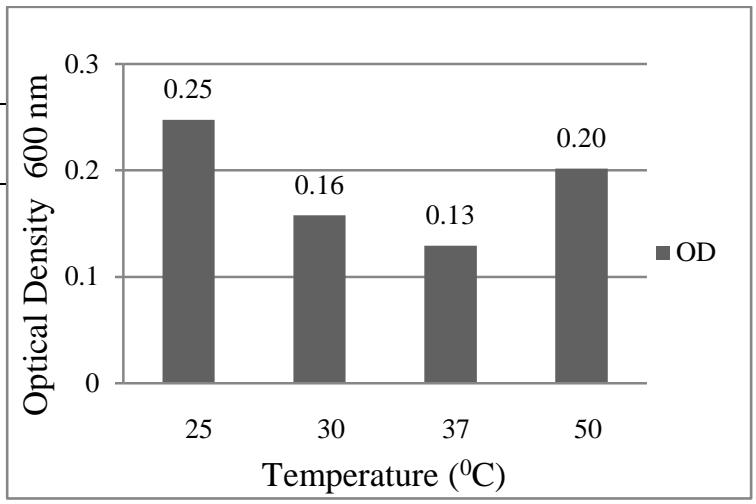

NR_043857.1

Figure 4. Population density of TG2 isolate in several temperature AB534593.1 growth on NB medium at 48 hours

Note: Identification was based on BLAST NCBI

Incubation of TG2 isolate in several temperature during 48 hours gave an optimum temperature growth for this Burkholderia sp. $25-30^{\circ} \mathrm{C}$ represented by optical density 0.28 at $600 \mathrm{~nm}$ wave length (Fig. 4). Colony counting of isolate incubated at $25^{\circ} \mathrm{C}$ showed the population of $176,15 \times 10^{5}$ $\mathrm{CFU} / \mathrm{ml}$. At temperature $50^{\circ} \mathrm{C}$, the absorbance was higher $(0.20)$ compared to 30 and $37^{\circ} \mathrm{C}(0.16$ and 0.13 respectively), but no colonies observed in solid media. At this temperature, bacteria were died and absorbance value corresponded to died cell. This result was in line with the mesophilic characteristic of Burkholderia .
Incubation of TG2 at $25^{\circ} \mathrm{C}$ during 9 days showed that the isolate started to grow after 24 hours (Fig. 5), following by a decrease of medium $\mathrm{pH}$ (Fig. 7), which was supposed related to organic acid production. At the same period, phosphate was solubilized and reached the maximum at day 6 with $54.78 \mathrm{ppm}$ of soluble phosphorus (Fig. 6). Measurement of phosphatase at day 6, corresponding to maximum activity of phosphate solubilization gave 5.99 unit $(\mu \mathrm{mol} / \mathrm{ml} / \mathrm{mn})$, decreased at day 7 and no activity recorded at day 9 , which related to the absence of bacterial growth at day 9. Indigenous PSB isolates could be used as biofertilizer agent for improving phosphorus availability in soil. 


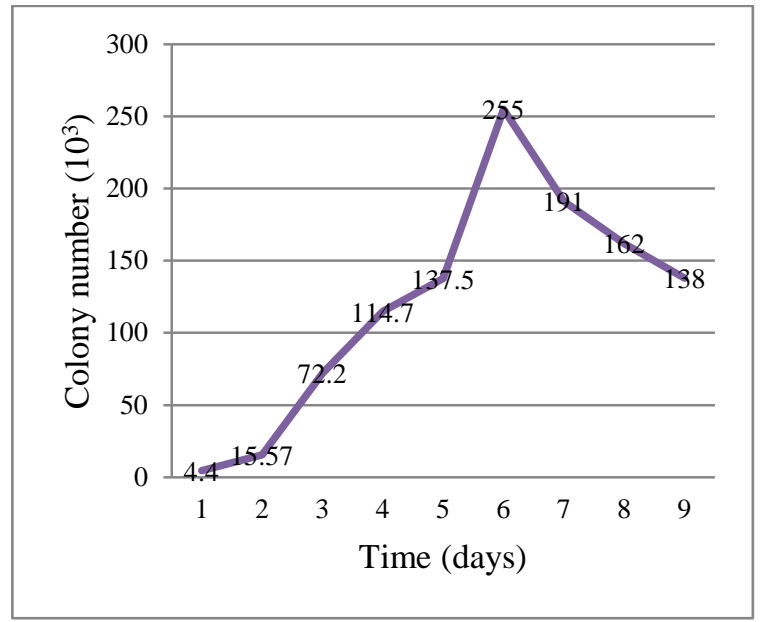

Figure 5. TG2 colony evolution during 9 days of incubation time at $25^{\circ} \mathrm{C}$

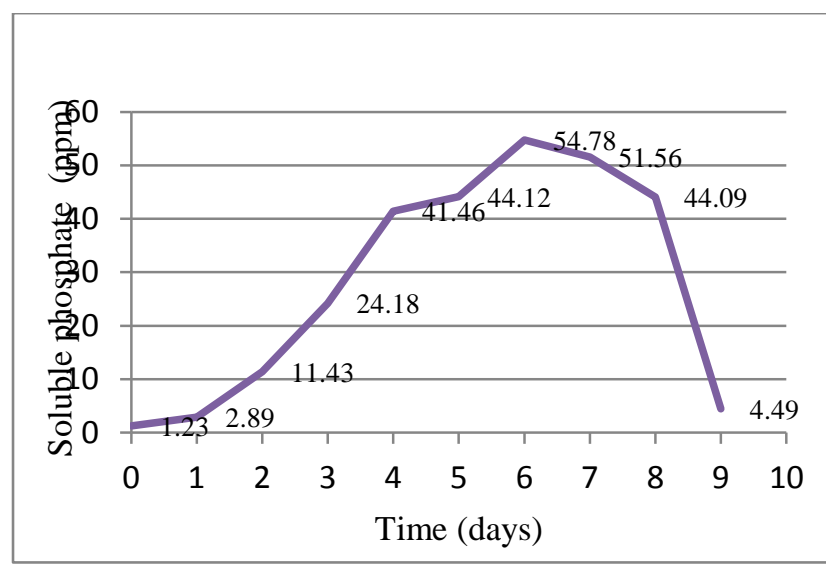

Figure 6. Phosphate solubilization in 9 days incubation of TG2 at $25^{\circ} \mathrm{C}$

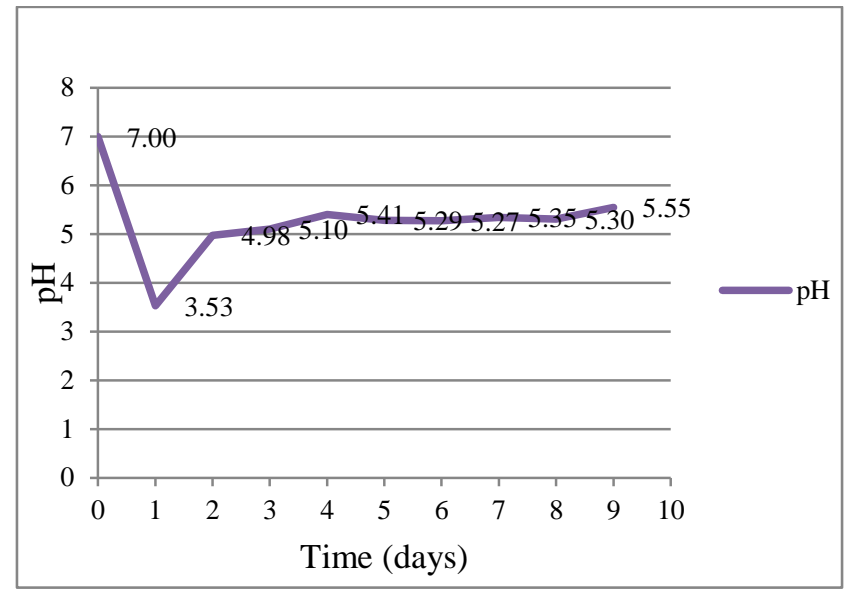

Figure 7. Change of $\mathrm{pH}$ during incubation time of $\mathrm{TG} 2$ at $25^{\circ} \mathrm{C}$

\section{Conclusion}

Eight indigenous phosphate solubilising bacteria, isolated from peat soil were characterized belonging to Burkholderia sp. and Novosphingobium nitrogenifigens. The best isolate TG2 has been proven for its capacity in solubilising phosphate and can be used as active agent of biofertilizer to increase the availability of phosphate in soil. The use of these bacteria should limit the energy to produce chemical fertilizer and therefore more advantageous economically and environmentally friendly.

\section{Acknowledgements}

This research is financed by PT Sinar Mas Agro Resources and Technology, Tbk. The authors thanked to the Management for the support. 


\section{References}

[1] Jayasankar R, Thyagarajan S. 2010. Constraints experienced by the rice farmers in adopting recommended biofertilizer practices. International Journal of Current Research. 7:018020.

[2] Krishnan HB, Benett JO. 2006. Rhizobium-legume symbiose: molecular signals elaborated by rhizobia that are important for nodulation. In: Plant-associated bacteria, Gnanamanickam, S.S. Springer, New York. 57-104.

[3] Fernandez LA, Zalba P, GOMEZ MAY, Sagardoy MA. 2007. Phosphate-solubilization activity of bacterial strains in soil and their effect on soybean growth under greenhouse conditions. In: Biology and Fertility of Soils. Springer, Berlin. 43: 805805.

[4] Gyaneshwar P, Kumar GN, Parekh LJ, Poole PS. 2002. Role of soil microorganisms in improving $\mathrm{P}$ nutrition of plants. Plant Soil. 245: 83-93.

[5] Shariati S, Alikhani HA, Pourbabaee A, Mohammadi L. 2013. The potential of application of different organic and inorganic carriers in insoluble phosphate solubilizing bacteria (Pseudomonas fluorescens) inoculants production process. International Journal of Agriculture: Research and Review . 3 (1): 176-183.

[6] Saber WIA, Ghanem KM, El-Hersh MS. 2009. Rock Phosphate Solubilization by Two Isolates Aspergillus niger and Penicillium sp. and their Promotion to Mung Bean Plants. Research Journal of Microbiology. 4 (7):235-250.

[7] Chuang CC, Kuo YL, Chao CC, Chao WL. 2007. Solubilization of inorganic phosphates and plant growth promotion by Aspergillus niger. Biol. Fet. Soils. 43: 575-584.

[8] Chen YP, Rekha PD, Arun AB, Shen FT, Lai WA, Young CC. 2006. Phosphate solubilising bacteria from subtropical soil and their tricalcium phosphate solubilising abilities. Appl. Soil Ecol. 34: 33-41.

[9] Gulati A, Rahi P, Vyas P. 2007. Characterization of phosphate solubilising fluorescent Pseudomonas from the rhizosphere of seabuckthorn growing in the cold deserts of Himalaya. Curr. Microbiol. 56:73-79.

[10] Stephen J, Jisha MS. 2011. Gluconic acid production as the principal mechanism of mineral phosphate solubilisation by Burkholderia sp. (MTCC 8369) . Journal of Tropical Agriculture. 49(1-2):99-103.

[11] Xiao CQ, Chi RA, Huang XH, Zhang WX, Qiu GZ, Wang DZ. 2008. Optimization for rock phosphate solubilisation by phosphate-solubilizing fungi isolated from phosphate mines. Ecol. Eng. 33: 187-193.
[12] Sundara Rao WVB, Sinha MK. 1963. Phosphate dissolving organisms in the soil and the rhizosphere. J. Agr. Sci. 33: 272278.

[13] Holt JG, Krieg NR, Sneath PHA, Staley JT, Williams ST. 2000. Bergey's Manual of Determinative Bacteriology. Ninth Edition. Williams\&Wilkins. Philadelphia.

[14] Tabatabai MA, Bremner JM. 1969. Use of pnitrophenylphosphate for assay of soil phosphatase activity. Soil Biol Biochem .1:301-307. 